\title{
Diving behavior of sperm whales in relation to behavior of a major prey species, the jumbo squid, in the Gulf of California, Mexico
}

\author{
R. W. Davis ${ }^{1, *}$, N. Jaquet ${ }^{2}$, D. Gendron ${ }^{3}$, U. Markaida ${ }^{4}$, G. Bazzino ${ }^{5}$, W. Gilly ${ }^{6}$ \\ ${ }^{1}$ Texas A\&M University, 5007 Avenue U, Galveston, Texas 77551, USA \\ ${ }^{2}$ Center for Coastal Studies, 115 Bradford Street, Provincetown, Massachusetts 02657, USA \\ ${ }^{3}$ Centro Interdisciplinario de Ciencias Marinas, Instituto Politécnico Nacional (CICIMAR-IPN), A. P. 592, La Paz, \\ Baja California Sur 23000, Mexico \\ ${ }^{4}$ Departamento de Aprovechamiento y Manejo de Recursos Acuáticos, El Colegio de la Frontera Sur, Calle 10 No. 246 , \\ Col. Centro, 24000 Campeche, Mexico \\ ${ }^{5}$ Centro de Investigaciones Biológicas del Noroeste (CIBNOR), Mar Bermejo No. 195, Col. Playa Palo de Santa Rita, \\ A. P. 592, La Paz, Baja California Sur 23000, Mexico \\ ${ }^{6}$ Hopkins Marine Station, Oceanview Boulevard, Stanford University, Pacific Grove, California 93950, USA
}

\begin{abstract}
Sperm whales occur worldwide and feed largely on meso- and bathypelagic squid, but little is known about the behavioral ecology of this predator and its prey. In the Gulf of California, sperm whales are thought to feed on the abundant jumbo (Humboldt) squid, an ecologically and commercially important species. In this study, we attached satellite-linked dive recorders to 5 sperm whales and pop-up archival transmitting tags to 3 jumbo squid in the same area and time period in order to record their diving behavior and movements. Most (91\%) deep dives by whales ranged from 100 to $500 \mathrm{~m}$ (average $418 \pm 216.0 \mathrm{~m}$ ) and lasted 15 to $35 \mathrm{~min}$ (average $27 \pm 9.1 \mathrm{~min}$ ). During daytime hours, jumbo squid spent about $75 \%$ of the time in the 200 to $400 \mathrm{~m}$ depth range, and sperm whales showed a similar dive-depth preference. The vertical distribution pattern of squid changed during the night, with squid spending about half the time at depths of $<200 \mathrm{~m}$ and the remainder at 200 to $400 \mathrm{~m}$. Although the whales shifted their nighttime diving to somewhat shallower depths, about $75 \%$ of dives remained in the 200 to $400 \mathrm{~m}$ depth range. Analysis of squid nighttime diving behavior, based on archival time-series data, showed that excursions into warm surface waters were often terminated by deep dives to typical daytime depths, after which the squid appeared to be relatively quiescent. Diving behavior by whales is thus consistent with the idea that they feed on jumbo squid at depth during the day, and we suggest that deep nighttime foraging may target squid that are recovering from stress after recent surface activity and are therefore more susceptible to predation.
\end{abstract}

KEY WORDS: Physeter macrocephalus · Dosidicus gigas · Diving behavior · Satellite telemeters · Movements $\cdot$ Predator $\cdot$ Prey $\cdot$ Gulf of California

- Resale or republication not permitted without written consent of the publisher

\section{INTRODUCTION}

Large predators play an important role in structuring ecosystems and maintaining biological diversity. Sperm whales Physeter macrocephalus and jumbo squid Dosidicus gigas are both major predators that spend much of their lives in one of the world's largest ecosystems, the mesopelagic zone (200 to $1000 \mathrm{~m}$ depth). They are among the largest members of this midwater community, where most species are either microscopic or only reach several $\mathrm{cm}$ in length (e.g. lanternfishes, hatchetfishes, euphausids and other crustaceans).

Sperm whales are transient members of the mesopelagic community because they make deep foraging dives to feed on meso- and bathypelagic organisms, especially squids (Kawakami 1980, Clarke 1986, 1996). 
Due to the worldwide abundance (360 000 to 1 million individuals; Whitehead 2002) and extreme size of sperm whales, total prey consumption is enormous. Worldwide annual predation on squids by sperm whales may exceed 100 million tonnes (Clarke 1996), similar to the biomass of marine fishes and invertebrates harvested annually by all commercial fisheries (see www.fao.org/docrep/007/y5600e/y5600e04.htm). Sperm whales thus provide a strong top-down force on mesopelagic ecosystems.

Jumbo squid also inhabit the mesopelagic zone where they are voracious consumers of a variety of midwater organisms (Nigmatullin et al. 2001), particularly myctophid lanternfishes (Markaida \& SosaNishizaki 2003). They also constitute an important forage species for large vertebrates (Markaida \& Hochberg 2005). Because jumbo squid are large (up to $50 \mathrm{~kg}$ ) and abundant, this species transfers large amounts of energy from lower trophic levels to top vertebrate predators.

Although sperm whales are generalists in terms of prey (Whitehead et al. 2003), specialization does appear to occur in a few places. In the Peru Current system off South America, sperm whales prey almost exclusively on large jumbo squid, an extremely abundant species that is the object of a large commercial fishery (Clarke \& Paliza 2001). A similar situation may exist in the Gulf of California, where jumbo squid are the most abundant species of large squid and also support a major fishery (Markaida et al. 2005). Because sperm whales typically feed on the most abundant prey (Kawakami 1980), it is likely that they feed heavily on jumbo squid in the Gulf of California. The spatial association of sperm whales with areas of established jumbo squid abundance, stable-isotope studies, and the analysis of whale stomach contents strengthen this assertion (Jaquet \& Gendron 2002, Jaquet et al. 2003, Ruiz-Cooley et al. 2004, 2006).

How sperm whales search for, detect, and capture their prey remains uncertain. Sperm whales probably use active sonar to locate prey, but no one has ever seen a sperm whale capture a squid. The central Gulf of California is a uniquely advantageous location to study the behavioral ecology of sperm whales and their squid prey. Sperm whales are abundant year-round and appear to feed heavily on jumbo squid, a species that is easily captured and amenable to tagging (Markaida et al. 2005, Gilly et al. 2006). In this study, we attached satellite-linked dive recorders to 5 sperm whales and 3 jumbo squid, in close proximity to one another in space and time, to record diving behavior and movements of both sperm whales and their presumed prey. To our knowledge, this is the first attempt to simultaneously study a mesopelagic predator and its prey using electronic tagging techniques.

\section{MATERIALS AND METHODS}

This study was conducted from late October to midNovember 2004 in the central Gulf of California, Mexico, near the town of Santa Rosalia (Baja California Sur; $27.3^{\circ} \mathrm{N}, 112.3^{\circ} \mathrm{W}$; Fig. 1), from where we made day trips to tag sperm whales and jumbo squid. This project was conducted in accordance with Animal Use Protocols at Texas A\&M University and under the scientific permit No. SGPA/DGVS 10168 from the Secretaria de Medio Ambiente Recursos Naturales.

Satellite tagging of sperm whales. We used the $8 \mathrm{~m}$ research vessel $\mathrm{R} / \mathrm{V}$ 'CICIMAR-XV' to locate and attach satellite telemeters to 5 female/immature sperm whales in a $25 \mathrm{~km}$ radius around Isla Tortuga $\left(27.5^{\circ} \mathrm{N}\right.$, $111.9^{\circ} \mathrm{W}$; Fig. 1), located about $46 \mathrm{~km}$ north-east of Santa Rosalia. We found the whales by listening continuously for their characteristic clicks using a

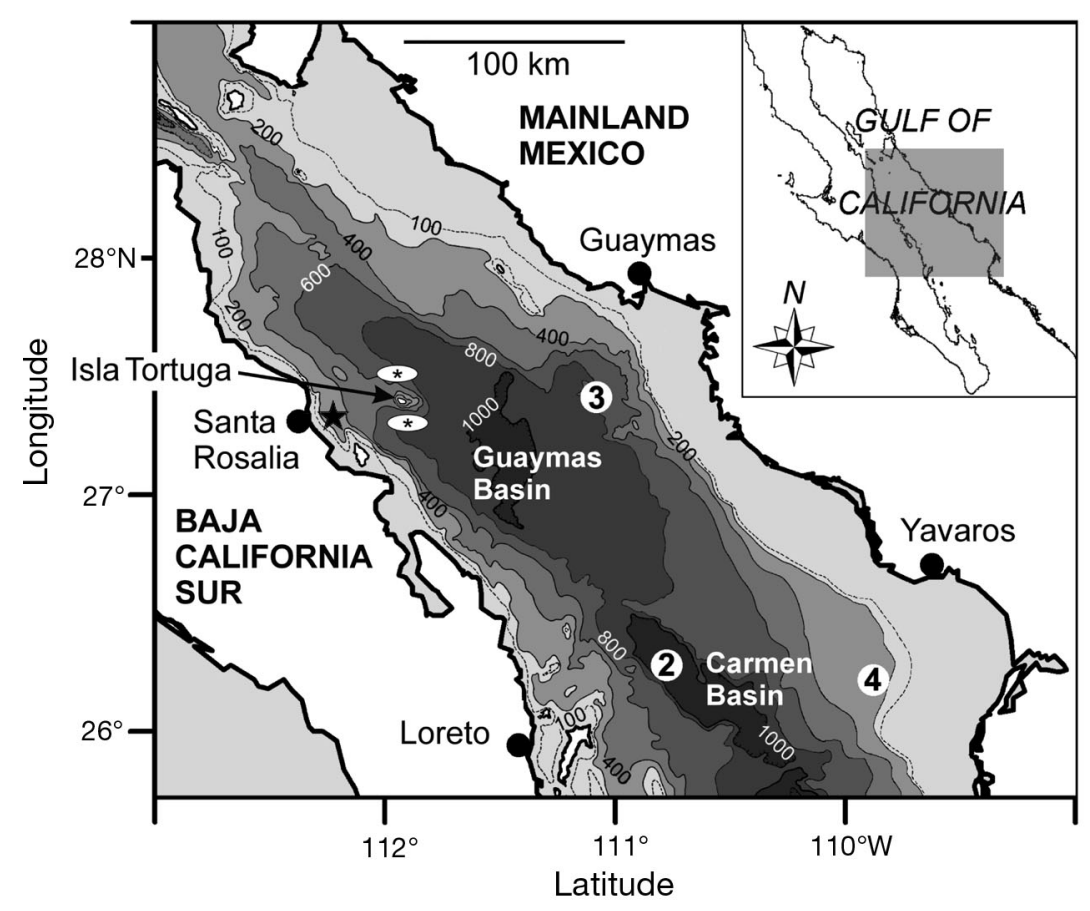

Fig. 1. Study area in the central Gulf of California. Whales were tagged in the general area of Isla Tortuga (white ellipses with stars) and squid off Santa Rosalia (black star). Locations from where squid PAT tags first reported to Service Argos are indicated by numbered white circles. See text for additional details. Depth contours in fathoms $(1$ fathom $=1.83 \mathrm{~m})$ 
2-element towed hydrophone array with a detection range of about $15 \mathrm{~km}$. Once a group of sperm whales was located, we followed them visually and acoustically using a directional hydrophone.

We tagged the whales with a satellite-linked dive recorder (SDR-T16, Wildlife Computers) and VHF radio transmitter (Advanced Telemetry Systems) that were cast in a torpedo-shaped float (referred to as a 'float tag', $28 \mathrm{~cm}$ long $\times 8 \mathrm{~cm}$ maximum diameter) of buoyant epoxy that was tethered to a $1.5 \mathrm{~m}$ stainless steel cable attached to a stainless steel barb. Each satellite telemeter had a discrete identification code and transmitted data every $20 \mathrm{~s}$ to Service Argos while at the surface. Only location classes (LC) of quality 0, 1 , 2 and 3 were used to calculate daily movements for each whale, and the predicated accuracies of these classes were $1.0,0.35$ and $0.15 \mathrm{~km}$, respectively. The depth range of the pressure transducer was 0 to $2000 \mathrm{~m}$, with a resolution of $4 \mathrm{~m}$. Data on maximum dive depths and the amount of time that an animal spent at depth were encoded into histograms with 14 programmable depth ranges $(8$ to $100 \mathrm{~m}$ plus those indicated in Fig. 3A). Thus, the minimum depth to be considered as a dive was $8 \mathrm{~m}$. Data on maximum dive duration were encoded into histograms with 14 programmable durations ( 0 to 5 min plus those indicated in Fig. 3B). The transmit buffer stored $24 \mathrm{~h}$ of data in $6 \mathrm{~h}$ histogram periods that corresponded to the local time (LT) for night (21:00 to 02:59 h LT), dawn (03:00 to 08:59 h LT), day (09:00 to 14:59 h LT) and dusk (15:00 to $20: 59 \mathrm{~h} \mathrm{LT}$ ). During the period that the telemeters were attached to the whales, sunrise occurred at ca. 06:43 $\mathrm{h}$ and sunset at 17:38 h LT.

We attached the telemeters near the dorsal hump with an $8 \mathrm{~m}$ carbon-fiber pole with a stainless steel rod (1 $\mathrm{cm}$ diameter, $60 \mathrm{~cm}$ long) at one end. The stainless steel barb was placed in a groove at the tip of the rod, and the telemeter was placed in an aluminum tube attached to the pole so that it was pulled out under slight drag from the stainless steel tether connecting it to the barb. The barb was pushed through the skin and into the blubber using the pole. Six tagging attempts were made, and 5 of them resulted in successful attachment of the telemeter. In the 6 th case, the whale began a dive before we could implant the barb. Once a whale was tagged, we used the VHF radio signal to track its movements for up to $2 \mathrm{~h}$ using a radio receiver and directional antenna. The barbs pulled out probably due to hydrodynamic drag on the tags after times ranging from $13 \mathrm{~h}$ to $212.5 \mathrm{~h}$ (see Table 1 ).

In addition to tagging whales, we recorded data for other group members. The location of the vessel, animal behavior, time of submergence (to the nearest $1 \mathrm{~s}$ ), location, and surfacing time (to the nearest $5 \mathrm{~s}$ ) were recorded on a small computer (Hewlett Packard
200 LX) linked to a Global Positioning System (GPS, Garmin 12XL). Surface time was recorded when an individual whale was seen breaking the surface after a dive and was followed at the surface until it dove. To identify each whale, we took digital images of the tail flukes at the start of each dive with a Canon EOS D1 with a 100 to $300 \mathrm{~mm}$ zoom lens (f4). Sperm whales were individually identified by marks on the trailing edge of their flukes (Arnbom 1987) and compared with a catalogue of 564 sperm whales identified in the Gulf since 1992 (N. Jaquet \& D. Gendron pers. obs.).

Average search time was measured as the elapsed time between deployment of the towed hydrodphone array and the first detection of sperm whale vocalizations. This variable provides an indication of sperm whale relative abundance (Jaquet \& Gendron 2002, Whitehead 2003).

Satellite tagging of jumbo squid. Pop-up archival transmitting (PAT) tags reveal horizontal movements and diving behavior of large pelagic animals that do not spend much time at the surface. These tags sample pressure and temperature (1 to 2 min sampling in our study) and archive this data in onboard memory. At a user-specified date and time, a metal pin to which the tag is tethered is actively corroded by electrolysis, thereby releasing the tag. The tag then floats to the surface and transmits a summary of the archived data to the Argos satellites. These data include time-at-depth distributions ( 1 to $2 \mathrm{~h}$ intervals in our study) as well as maximum and minimum depth for each interval. Transmissions also provide the position of the floating tag until the batteries are exhausted after 1 to $2 \mathrm{wk}$.

Three jumbo squid (mantle lengths of 77 to $83 \mathrm{~cm}$ ) were tagged (PAT 3.0 tags, Wildlife Computers) in conjunction with a previously described study (Gilly et al. 2006), and their original identification as Tags 2 to 4 is retained here to avoid confusion. All tags were deployed within $4 \mathrm{~km}$ of Santa Rosalia during the nights of October 25 (Tags 2 and 3) and October 26, 2004 (Tag 4). Tags remained attached to the squids for 5 to $7 \mathrm{~d}$, during which data were continuously stored in memory.

Archival time-series data were recovered from 1 squid tagged in 2002 (September 12 to October 14) with a small archival tag (LTD1100, Lotek Wireless) at the same area off Santa Rosalia (Gilly et al. 2006). Based on the proximity of the recapture site, this squid probably remained in the area between Santa Rosalia and Isla Tortuga for the entire time it carried the tag. The sampling interval (pressure and temperature) was either 2 or $4 \mathrm{~min}$.

Data analyses. Sperm whale and PAT tag locations were mapped using standard Geographic Information System (GIS) software (ArcView, ESRI). Dive data for sperm whales were analyzed using SATPAK software (Wildlife Computers). For sperm whales, we analyzed 
the maximum depth and duration of dives encoded into histograms with programmable ranges. Because sperm whales are thought to dive from the surface to their feeding depth, we think that the maximum depth of dives more accurately reflects where the whales are feeding than do time-at-depth data, which include transit times to and from the surface. In contrast, timeat-depth directly indicates where the continuously submerged squid spend their time, presumably much of which is associated with foraging. The maximum depth and duration of dives for sperm whales and time-at-depth for squid were therefore determined for the four $6 \mathrm{~h}$ periods defined above (dawn, day, dusk, night). To avoid the possibility that whale diving behavior was altered for a short time after tagging (Amano \& Yoshioka 2003), the first $6 \mathrm{~h}$ period was excluded from our analysis of whale diving behavior.

Data from squid tags were analyzed using Igor Pro (Wavemetrics) and Matlab (Mathworks). Deep-diving events were defined as descents that showed an essentially monotonic change in depth of $\geq 100 \mathrm{~m}$ with no restriction on rate of change. Most of these descents occurred during nighttime and were rapid. Once these events were identified by a recursive procedure, the cumulative probability density function was determined for the occurrence of a descent above a given temperature.

Chi-square tests and a Kruskal-Wallis test were used to analyze differences in the frequency of deep dives and the average depths achieved in relation to time of day. A Mann-Whitney test was used to test day versus night differences in squid. Average values are shown with SD.

\section{RESULTS}

\section{Sperm whale movements and diving behavior}

We spent 6 d searching for sperm whales and tagging them in the area around Isla Tortuga, generally in water deeper than 1000 m (Fig. 1). Groups of female and immature sperm whales were abundant in this area, and it took us an average of $57 \pm 43.5 \mathrm{~min}$ from the time we placed the towed hydrophone array in the water to the time we detected the first sperm whale click, and an additional $63 \pm 40.5 \mathrm{~min}$ until the first sperm whale was sighted.

Two sperm whales were tagged on November 4 (Group 1) and 3 more on November 6 (Group 2). Two of these whales ( 1 each in each group) were accompanied by small calves. Whales typically reacted to tagging with a tail stroke followed by a shallow dive, but no unusual behavior or aggression towards the boat was ever observed. The tags remained attached to the whales for up to $212.5 \mathrm{~h}$ (see Table 1).

After tagging, the whales in Groups 1 and 2 remained together, respectively. The average distance between whales within a group was $7.8 \mathrm{~km}$, while the average distance between individuals from different groups was $15.6 \mathrm{~km}$. Whale 1 provided the most locations (60 over $212.5 \mathrm{~h}$ ), while whale 2 provided the fewest (4 over $13.0 \mathrm{~h}$ ) (Table 1). On average, the 5 satellite tags provided $0.3 \pm 0.11$ locations per hour. The average transit speed was $2.7 \pm 1.02 \mathrm{~km} \mathrm{~h}^{-1}$, and the average horizontal displacement (maximum distance from the point of tagging) was $27 \pm 16.2 \mathrm{~km}$ (Table 1). The tagged whales generally stayed in water that was deeper than $1000 \mathrm{~m}$ (Fig. 2). Although the whales were from 2 different groups (no photoidentification matches between groups), they generally remained in the area around Isla Tortuga.

Most (ca. $74 \%$ ) dives were shallow (8 to $100 \mathrm{~m}$ ) and of short duration (0 to $5 \mathrm{~min}$ ). We believe that these dives were associated with resting and/or socializing, and were not included in our analysis. For brevity, we refer to dives deeper than $100 \mathrm{~m}$ and longer than $5 \mathrm{~min}$ as deep dives.

Ninety-one percent of deep dives ranged from 100 to $500 \mathrm{~m}$, representing $88 \%$ of the total submerged time associated with deep diving (Fig. 3A). Dives to greater depths were infrequent, and the maximum depths

Table 1. Physeter macrocephalus. Individual movements of 5 tagged sperm whales. Elapsed time is total time between tagging and the last satellite-based location. Locations refer to positions received from Argos. Total distance is minimum cumulative horizontal distance traveled based on locations in Fig. 2. Transit speed is total distance divided by elapsed time. Displacement is horizontal straight-line distance from the location of tagging to final location

\begin{tabular}{|c|c|c|c|c|c|c|c|}
\hline Whale & Group & $\begin{array}{l}\text { Elapsed } \\
\text { time (h) }\end{array}$ & $\begin{array}{l}\text { Number of } \\
\text { locations }\end{array}$ & $\begin{array}{l}\text { Locations } \\
\mathrm{h}^{-1}\end{array}$ & $\begin{array}{l}\text { Total distance } \\
\qquad(\mathrm{km})\end{array}$ & $\begin{array}{l}\text { Transit speed } \\
\qquad\left(\mathrm{km} \mathrm{h}^{-1}\right)\end{array}$ & $\begin{array}{l}\text { Displacement } \\
(\mathrm{km})\end{array}$ \\
\hline 1 (LNR123) & 1 & 212.5 & 60 & 0.28 & 640 & 3.0 & 55 \\
\hline 2 (LNR120) & 1 & 13.0 & 4 & 0.31 & 23 & 1.7 & 14 \\
\hline 3 (LSB125) & 2 & 37.4 & 10 & 0.27 & 161 & 4.3 & 24 \\
\hline 4 (LSL120) & 2 & 40.1 & 7 & 0.17 & 107 & 2.6 & 26 \\
\hline 5 (SNB124) & 2 & 14.8 & 7 & 0.47 & 31 & 2.0 & 18 \\
\hline Mean & & 63.5 & 18 & 0.3 & 192 & 2.7 & 27 \\
\hline SD & & 84.18 & 23.8 & 0.11 & 256.6 & 1.02 & 16.2 \\
\hline
\end{tabular}




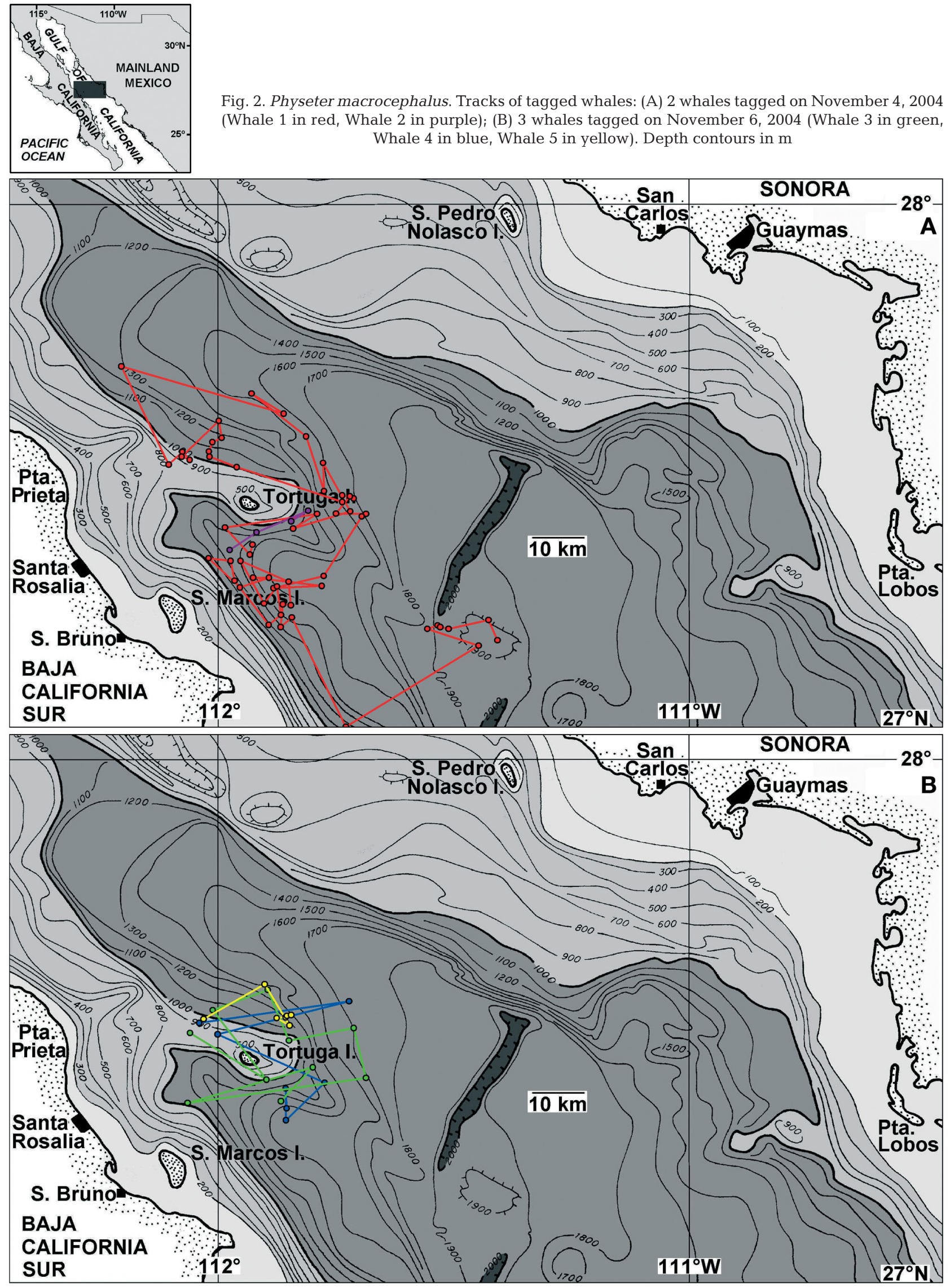




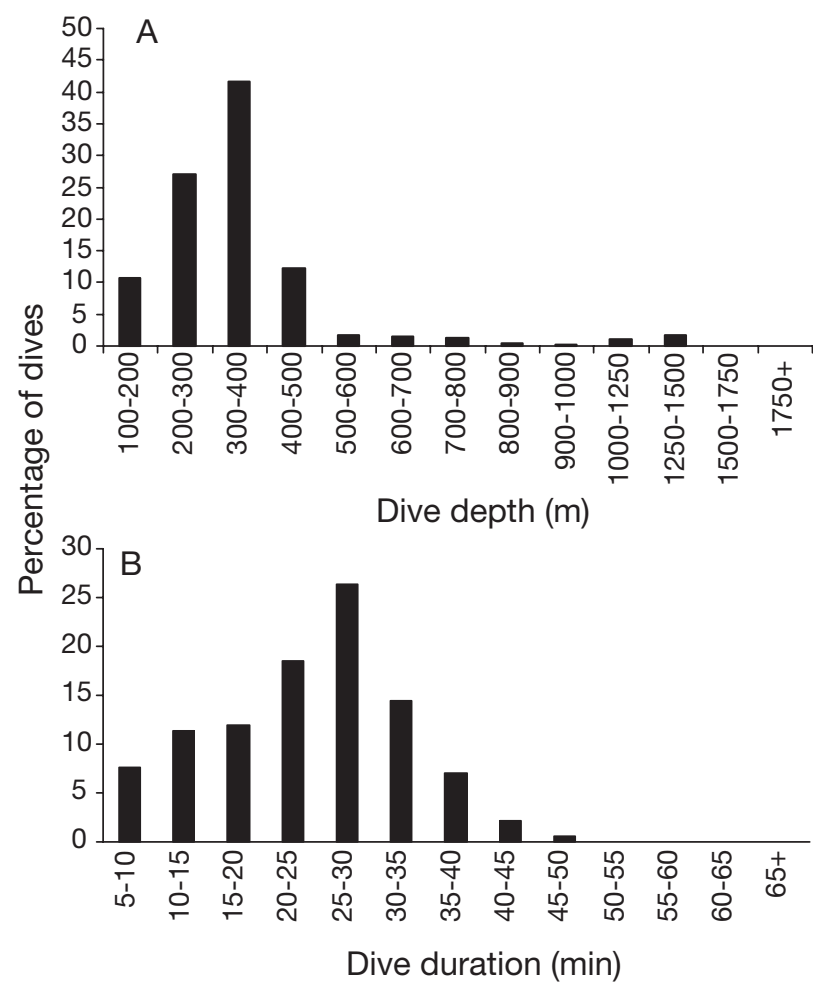

Fig. 3. Physeter macrocephalus. Distribution of (A) depth and (B) duration of deep dives $(>100 \mathrm{~m})$ as derived from satellitetag data

reached were 1250 to 1500 m (8 dives or $1.8 \%$ ). Average depth of all deep dives was $418 \pm 216.0 \mathrm{~m}(\mathrm{n}=390)$. Most deep dives (70\%) lasted for 15 to 35 min; only $3 \%$ of the dives were longer than $40 \mathrm{~min}$ (Fig. 3B). The average duration of all deep dives was $27 \pm 9.1 \mathrm{~min}$ ( $\mathrm{n}=314$ ). During the course of this study, 22 surface times ranging from 4.6 to $9.2 \mathrm{~min}(8.0 \pm 1.20 \mathrm{~min})$ were recorded for 11 whales.

Statistical tests were employed to analyze differences in the characteristics of deep diving in the four $6 \mathrm{~h}$ time periods (dawn, day, dusk, night). Chi-square tests revealed no significant differences in the number of deep dives among the 4 periods $\left(\chi^{2}=0.9848, \mathrm{df}=3\right.$, $\mathrm{p}>0.05)$ or in the number of dives longer than $5 \mathrm{~min}$ $\left(\chi^{2}=6.1057\right.$, df $\left.=3, \mathrm{p}>0.05\right)$. However, a KruskalWallis test $(H=10.304, \mathrm{df}=3, \mathrm{p}=0.0162)$ indicated that daytime dives $(462.5 \pm 303.1 \mathrm{~m}, \mathrm{n}=64)$ were on average deeper than those during nighttime (381 \pm $128.3 \mathrm{~m}, \mathrm{n}=104)$. Dawn and dusk periods had respective average dive depths of $443.6 \pm 303.1 \mathrm{~m}(\mathrm{n}=94)$ and $399.6 \pm 166.1 \mathrm{~m}(\mathrm{n}=126)$.

\section{Diving behavior of squid in relation to sperm whales}

All squid tags were deployed within a few $\mathrm{km}$ of Santa Rosalia. Tag 2 released from the squid on sched- ule and surfaced in the Carmen Basin to the south-east (Fig. 1). The other 2 tags detached prematurely and drifted for $4 \mathrm{~d}$ before transmitting, so the exact locations of these squid at the time of detachment are uncertain. A south-eastward drift of all 3 tags (up to $30 \mathrm{~km} \mathrm{~d}^{-1}$ ) was consistently observed, based on the positions transmitted by Service Argos (not shown), and it is therefore likely that both tags first surfaced a considerable distance to the north-west. Thus, as the 3 tagged squid migrated away from Santa Rosalia, they almost certainly passed through the area inhabited by the tagged whales.

Jumbo squid ranged throughout the water column to a depth of $500 \mathrm{~m}$, thus overlapping with the bulk of whale dive-depths (Fig. 4). Time-at-depth distributions of squid during the 4 time periods are compared with the corresponding dive-depth distributions of sperm whales in Fig. 5. During the day (Fig. 5A), the mode of each distribution was 300 to $400 \mathrm{~m}$, with the 200 to $400 \mathrm{~m}$ zone accounting for about $75 \%$ of each data set. During the night, squid moved to shallower depths (Fig. 5B). All day and night values for squid time-atdepth are significantly different ( $\mathrm{p} \leq 0.027$, MannWhitney test) except for the 200-300 m depth bin. Differences in values for 100-200 m and 300-400 m are significant at $\mathrm{p} \leq 0.001$. Whales also shifted their nighttime diving behavior in the same direction, but the total fraction of dives to 200 to $400 \mathrm{~m}$ remained unchanged.

An increased tendency for squid to inhabit the 100 to $200 \mathrm{~m}$ zone was also evident in the dusk (Fig. 5C) and dawn (Fig. 5D) distributions. Based on an analysis of

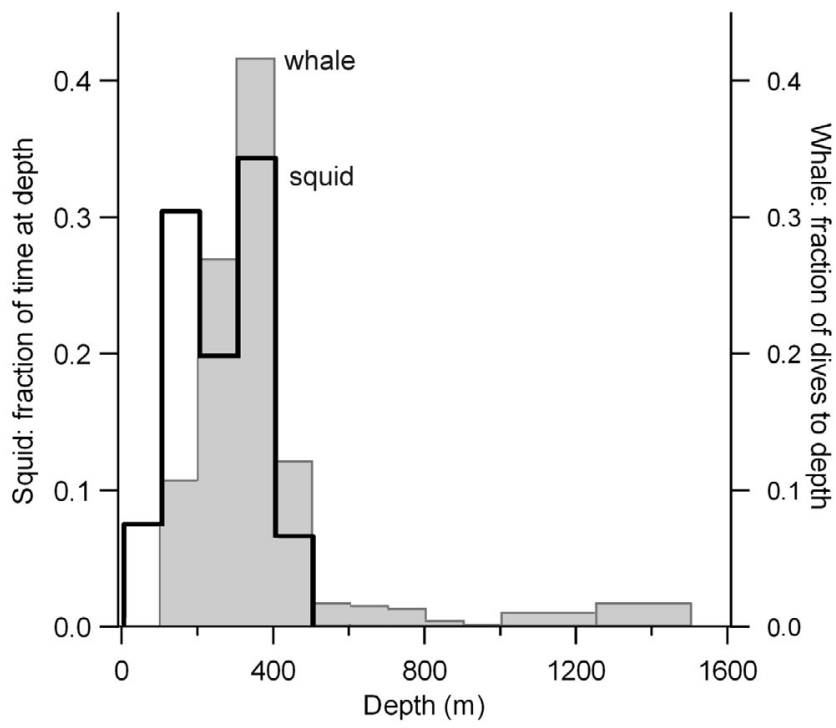

Fig. 4. Dosidicus gigas and Physeter macrocephalus. Overall comparison of squid of time-at-depth data (white bars) and whale dive-depth distribution (shaded bars, replotted from Fig. 3). All data derived from satellite tags 
squid data in 1 or $2 \mathrm{~h}$ bins (not shown), this distribution pattern largely occurred during the dark hours before dawn and after dusk. Whale diving behavior during dawn and dusk remained similar to that during the night.

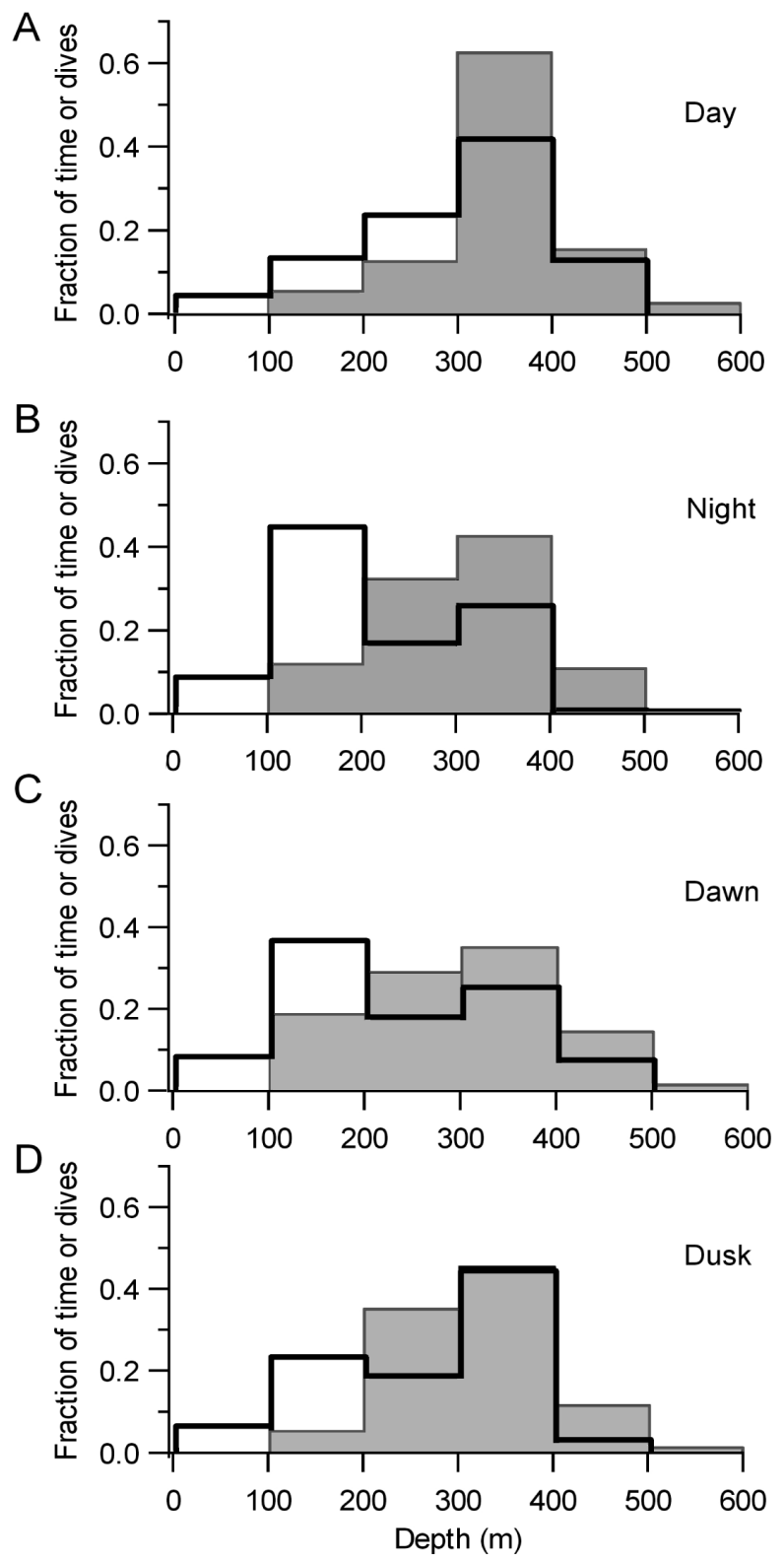

Fig. 5. Dosidicus gigas and Physeter macrocephalus. Vertical distributions of squid and sperm whale dives revealed by satellite tagging. (A) Daytime (09:00-14:59 h LT) distributions for both whales (shaded bars) and squid (white bars) peak at 300-400 m. (B) Nighttime (21:00-02:59 h LT) distribution for squid shows the majority of time was spent at shallow depths, while whales continued to make most of their dives to depths of 200-400 m. (C) Dusk (15:00-23:59 h LT) distributions are similar for both species, but squid spend more time at 100-200 m. (D) Dawn (03:00-08:59 h LT) distributions for whales (shaded bars) and squid (white bars) are fairly similar. Both distributions peak at $300-400 \mathrm{~m}$
Change in the vertical distribution of squid is not a simple diel migration, because the squid move up and down in the water column a great deal during the night. In many cases, particularly during hours of darkness, the overall vertical excursions during a 1 or $2 \mathrm{~h}$ segment spanned the range from $<100 \mathrm{~m}$ to $>300 \mathrm{~m}$ (Fig. 6). It is visually obvious that many of the shallower nighttime data points are paired with vertical excursions to great depths, which means this squid was making rapid nighttime transitions between near-surface waters and 'typical' daytime depths of 300 to $400 \mathrm{~m}$.

Rapid nighttime transitions of this type were directly revealed in time-series data obtained from an archival tag deployed in the same area (Gilly et al. 2006). Dives of $>100 \mathrm{~m}$ are marked by arrows or arrowheads in Fig. 7, and such events typically occurred during hours of darkness. Two points are suggested by the records in Fig. 7. First, deep dives tended to terminate excursions into water warmer than $22^{\circ} \mathrm{C}$. Second, the squid showed comparatively little vertical movement during the time at depth immediately after such a dive. We believe that both points are related to physiological stress that develops during high-levels of activity in warm water.

A relationship between temperature and deep-diving is evident in the cumulative probability of the squid making a descent after encountering water above a certain temperature (i.e. the time to first dive). Cumulative probability functions for 22 to $27^{\circ} \mathrm{C}$ are shown in Fig. 8A. Below $22^{\circ} \mathrm{C}$ (typically at $\sim 75 \mathrm{~m}$ ), the half-time to making a descent (i.e. when $\mathrm{p}=0.5$ ) was $\sim 1 \mathrm{~h}$, but at warmer temperatures, the half-time fell to only a few minutes (Fig. 8B). Cumulative probability functions for all temperatures $>18^{\circ} \mathrm{C}$ contain an extremely fast component that appears as a vertical intercept (Fig. 8A), indicating that a dive occurred within the first sample period ( 2 or $4 \mathrm{~min}$ ). The value of this 'immediate-dive intercept' is highly temperature-dependent (Fig. 8B). Because nighttime activity in near-surface waters presumably reflects foraging, it undoubtedly entails considerable activity, both in vertical and horizontal directions. High temperature may thus lead to physiological stress, and we propose that deep nighttime dives might provide thermal relief.

A recovery-related function for deep diving is also suggested by the fact that the squid appeared to be quiescent immediately following a deep dive (e.g. circles in Fig. 7). A total of 16 deep-diving events were identified in the archival tag data set that (1) occurred during nighttime, (2) followed exposure to temperatures of $\geq 21.5^{\circ} \mathrm{C}$, and (3) took the squid to a depth of $\geq 250 \mathrm{~m}$ (examples of 3 such events are indicated by downward arrows in Fig. 7). Instantaneous vertical velocity (determined between successive points) during a period of 1 to $1.5 \mathrm{~h}$ immediately after a dive 


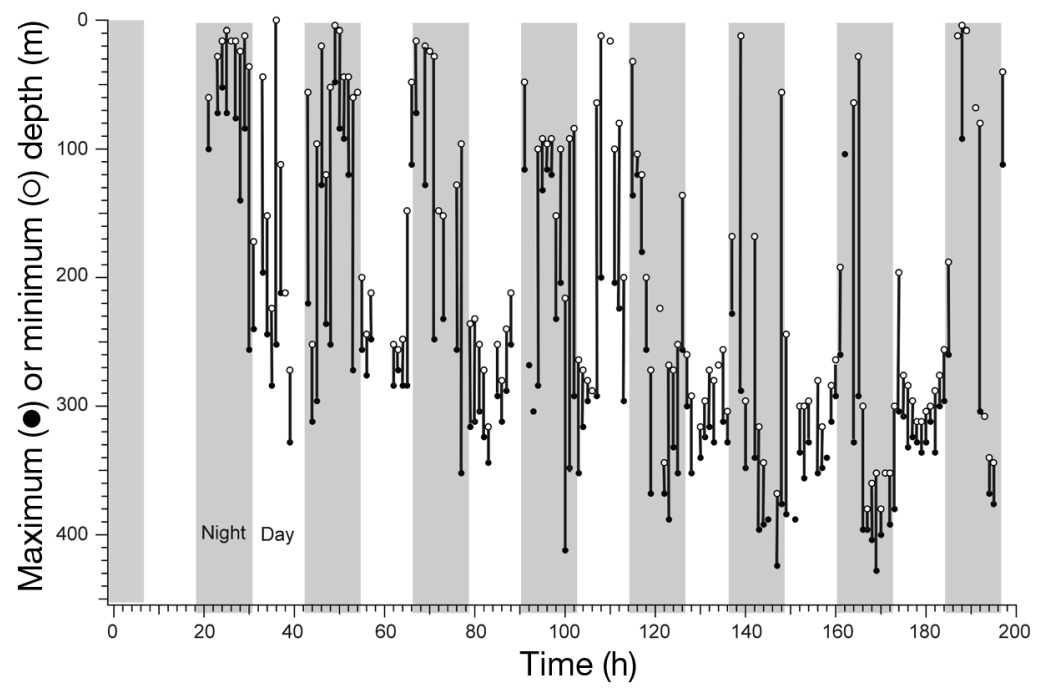

Fig. 6. Dosidicus gigas. Vertical excursions in $1 \mathrm{~h}$ periods by the squid carrying PAT Tag 2. ०: minimum depth, •: maximum depth, solid lines: overall vertical excursion. Shaded areas: dark hours (sunset to sunrise LT), open areas: light hours (sunrise to sunset LT); $t_{0}$ is local midnight. The overall excursion during many $1 \mathrm{~h}$ periods was very large, consistent with a rapid vertical migration between 'typical' daytime and nighttime depths as defined by summary histograms. Data from the other 2 tags were similar (not shown)

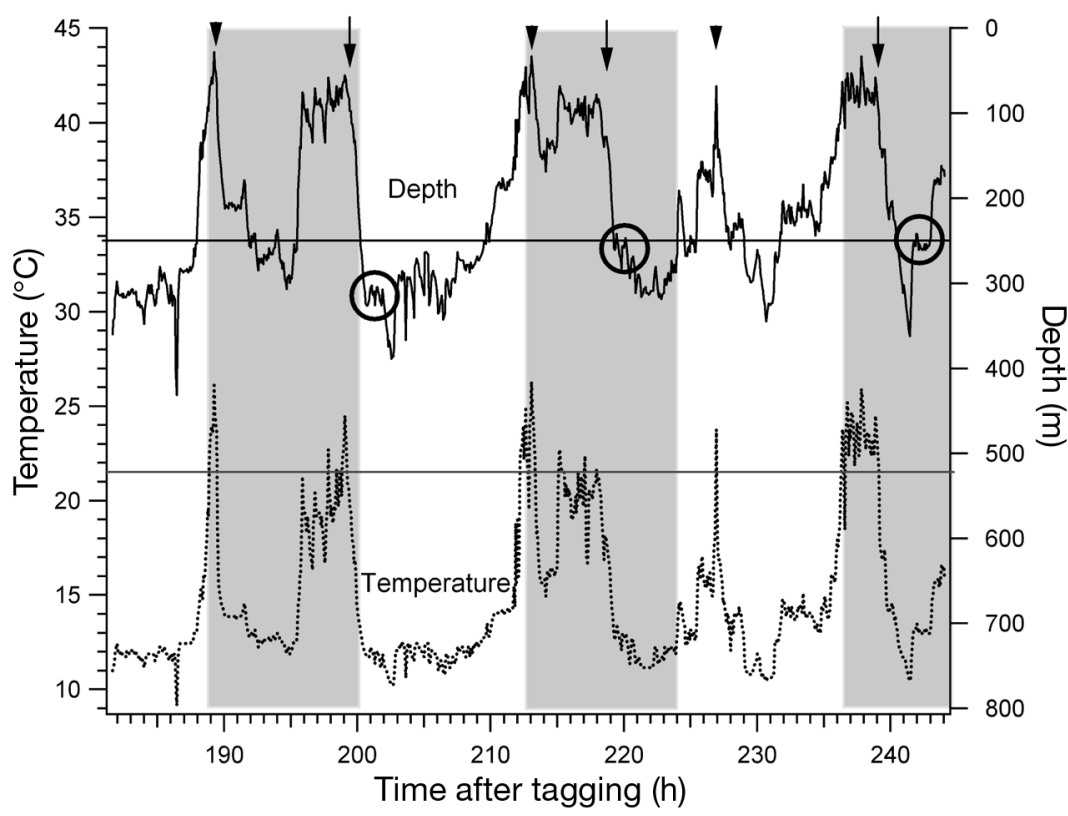

Fig. 7. Dosidicus gigas. Deep diving behavior at night. Representative depth (solid trace) and temperature (dotted trace) data are shown for an archival tag (period plotted corresponds to September 21-22, 2002). The squid was released at $t_{0}$ (not shown). Light gray bars represent the period between local sunset and sunrise. Arrowheads and arrows denote deep-diving events with overall depth changes of $>100 \mathrm{~m}$. Solid black line at $250 \mathrm{~m}$ represents approximate upper boundary of the oxygen minimum layer. Arrows indicate nighttime events that specifically took the squid to $\geq 250 \mathrm{~m}$ depth after an excursion into water warmer than $21.5^{\circ} \mathrm{C}$ (gray line). Circles indicate periods after deep dives in which the squid showed relatively little vertical movement tended to be lower than that computed for all activity at depths of $\leq 150 \mathrm{~m}$ (Fig. $8 \mathrm{C})$. The distribution of all nighttime velocities deeper than $250 \mathrm{~m}$ was intermediate between the distributions in Fig. 8C (not shown).

\section{DISCUSSION}

This study employed satellite-tag technology to examine the diving behavior of an apex vertebrate predator, the sperm whale, in relation to that of its presumed prey, the jumbo squid. Although these methods have been employed on many species of large pelagic fish and mammalian predators, to our knowledge they have not been simultaneously applied to both predator and prey species in the same area, and only recently used with squids (Gilly et al. 2006). Satellite telemeters and PAT tags are particularly useful to study species that are not subject to commercial fishing efforts due to legal, economic or biological factors. This cotagging approach should yield new insights into predator-prey interactions with any pelagic species that are large enough to carry electronic tags.

During the study, sperm whales were abundant around Isla Tortuga, and the average search time for sperm whales (57 min) was much shorter (by 86 to $98 \%$ ) than that reported for other areas (Whitehead \& Kahn 1992, Jaquet \& Gendron 2002). During 6 days at sea, we identified 74 individual sperm whales in an area of less than $70 \mathrm{~km}^{2}$, confirming their high abundance in the study area and during the study period. Jumbo squid were also extremely abundant, at least on the Santa Rosalia fishing grounds. During the period of this study, commercial fishing efforts were robust, and landings were probably about 100 tonnes ( 10000 squid) per night (W. Gilly \& U. Markaida unpubl. data).

\section{Sperm whale movements}

For the most part, the whales tagged during this study remained in the gen- 
A

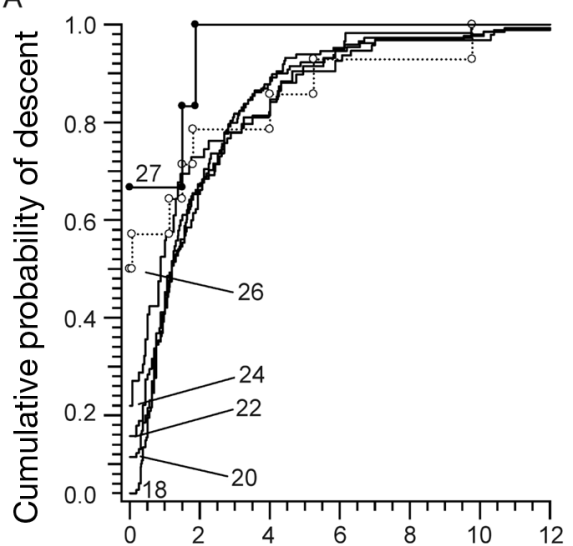

Time at given temperature $(h)$
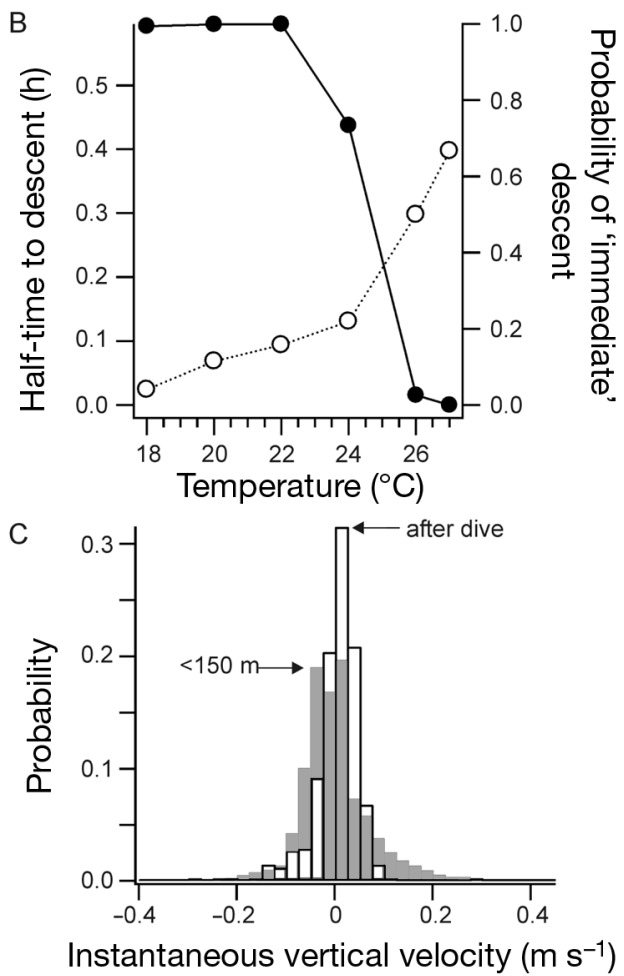

Fig. 8. Dosidicus gigas. Kinetics of deep-diving behavior. (A) Cumulative probability density functions computed from all archival data for descents initiated after the squid spent time above the indicated temperature levels $\left({ }^{\circ} \mathrm{C}\right)$. Lines point to first points at $2-4 \mathrm{~min}$, which appear as vertical intercepts. See text for details. Numbers of descents identified for each temperature were $148\left(18^{\circ} \mathrm{C}\right), 130\left(20^{\circ} \mathrm{C}\right), 95\left(22^{\circ} \mathrm{C}\right), 59\left(24^{\circ} \mathrm{C}\right), 15\left(26^{\circ} \mathrm{C}\right)$ and $7\left(27^{\circ} \mathrm{C}\right)$. (B) Half-time to making a descent (, solid line) highly temperature-dependent between $22-28^{\circ} \mathrm{C}$. Probability of 'immediate' descent $(O$, dotted line) refers to diving that occurred within 1 sample period of 2 or $4 \mathrm{~min}$. (C) Distributions of instantaneous vertical velocities computed from nighttime archival data (sunset to sunrise) for all activity at depths $\leq 150 \mathrm{~m}$ (shaded bars; 4111 data points) and activity occurring over a $1-1.5 \mathrm{~h}$ period following a deep dive (white bars; 412 data points). Squid tended to move less in the vertical dimension following a deep dive. Negative velocity is descending eral area of Isla Tortuga: even after $9 \mathrm{~d}$, Whale $1-$ which showed the most extensive horizontal movement-was only $55 \mathrm{~km}$ from where it was tagged. During this time, the whale traveled a minimum horizontal distance of $640 \mathrm{~km}$ at an average transit speed of $72 \mathrm{~km} \mathrm{~d}^{-1}\left(3.0 \mathrm{~km} \mathrm{~h}^{-1}\right)$ (Table 1). Similarly, the average transit speeds of Whales 3 and 4 were 103 and $62 \mathrm{~km}$ $\mathrm{d}^{-1}$ (4.3 and $2.6 \mathrm{~km} \mathrm{~h}^{-1}$ ), respectively, which are comparable with values reported previously (Whitehead 2003). Although the whales in our study traveled up to $100 \mathrm{~km} \mathrm{~d}^{-1}$, they remained in a relatively small area $(65 \times 56 \mathrm{~km}$ for Whale 1). Extensive movements in such a concentrated area suggest successful foraging, because when feeding success is low, sperm whales do not remain in an area and travel elsewhere in a fairly straight line (Whitehead 1996, Jaquet \& Whitehead 1999).

Although large quantities of jumbo squid were captured close to shore by the fishery off Santa Rosalia in water that was generally $<400 \mathrm{~m}$ deep, sperm whales remained substantially further offshore in water deeper than $1000 \mathrm{~m}$. This observation is consistent with data on females and immature whales from the South Pacific (Whitehead 2003). In the present case, it is not clear why the whales would avoid the inshore area that was rich in squid. Typically up to 200 small fishing boats operate out of Santa Rosalia between dusk and midnight (W. Gilly \& U. Markaida unpubl. data), and it seems likely that such a volume of boat traffic would be a deterrent to sperm whales. In addition, the fishing grounds lie on the western edge of a southward-running box canyon (Fig. 1), and such underwater topography may also be a deterrent. Alternatively, the abundance of jumbo squid in the area inhabited by the whales may also be extremely high, but knowledge of this region is limited.

\section{Sperm whale diving behavior}

The majority $(91 \%)$ of dives recorded in this study were 100 to $500 \mathrm{~m}$ deep, with only 13 dives (3\%) exceeding $1000 \mathrm{~m}$. Since the whales remained in water deeper than $1000 \mathrm{~m}$ (Fig. 2), nearly all dives (overall mean depth of $418 \mathrm{~m}$ ) were not limited by ocean depth. Other studies have found that sperm whales descend more frequently to greater depths (Whitehead 2003, Amano \& Yoshioka 2003, Watwood et al. 2006). We propose that the smaller average deep-dive depth observed in the present study is related to the vertical distribution of jumbo squid.

In our study, tagged squid occupied the 100 to $500 \mathrm{~m}$ zone, the same region to which the whales dove over $90 \%$ of the time, consistent with the idea that whales were primarily preying on jumbo squid of large body 
size (Clarke \& Paliza 2001, Ruiz-Cooley et al. 2004, 2006). Whales did occasionally dive beyond $500 \mathrm{~m}$, especially during daytime when the squid were deep, and we assume these dives also represent foraging. Adult jumbo squid have been observed at depths of $>1000 \mathrm{~m}$ in the Guaymas Basin during daytime remotely operated vehicle (ROV) operations (B. Robison \& B. Seibel pers. comm.), but other mesopelagic prey species could also be involved in these unusually deep and highly infrequent dives.

The average duration of deep dives $(27 \mathrm{~min}$ ) in our study was also substantially shorter than that reported for other areas where sperm whale foraging dives last 35 to $55 \mathrm{~min}$; however, there is much variability in dive duration between genders and among regions (Gordon \& Steiner 1992, Jaquet et al. 2000, Amano \& Yoshioka 2003, Whitehead 2003, Drouot et al. 2004, Watwood et al. 2006). The shorter average duration we observed probably reflects the shallower depths to which whales dove in the present study, and a similar correlation was reported for male sperm whales in shallow (40 to $70 \mathrm{~m}$ ) waters where dive durations were generally 10 to $15 \mathrm{~min}$ and the longest dive only $21 \mathrm{~min}$ (Scott \& Sadov 1997).

Despite the shorter dive durations recorded in our study, the average time spent on the surface between dives (average $=8.0 \mathrm{~min}$ ) was similar to values recorded for sperm whales in other areas (Jaquet et al. 2000, Drouot et al. 2004, Watwood et al. 2006). Thus, the absence of a correlation between dive duration and time at the surface may be a common feature of sperm whale behavior.

\section{Sperm whales and jumbo squid diving behavior}

There was no significant difference in the number of deep dives by sperm whales as a function of time of day (dawn, day, dusk or night). These results suggest that foraging effort by the whales remained fairly constant throughout the $24 \mathrm{~h}$ day, consistent with the observation that there was no relationship between stomach fullness and time of day for whales harvested in the Bering Sea, South Africa or Antarctica (Best 1999).

Jumbo squid clearly showed a diel change in vertical distribution, and tended to spend daytime at a substantially greater depth than at night (Fig. 5). This vertical migration qualitatively matches the behavior of their main prey in this region of the Gulf, myctophid fishes (Markaida \& Sosa-Nishizaki 2003). Consequently, squid probably forage both day and night on this resource.

Sperm whales did not exhibit a parallel change in diving behavior. During daytime, both whales and squid were found primarily at depths of 300 to $400 \mathrm{~m}$, consistent with the idea that the whales were foraging where the probability of encountering squid was highest. The nighttime whale dive-depth distribution (Fig. 5B) was broader and shallower than during daytime (Fig. 5A), but it clearly does not match the pronounced shift in the squid distribution.

Although changes in the vertical distribution of jumbo squid can be described as a diel migration, this species evidently does not spend the entire night at shallow depths. This is a critical feature. Rapid, transient excursions by squid near the surface at night to typical daytime depths are common (Figs. 6 \& 7; see also Gilly et al. 2006), and this phenomenon partially accounts for the fact that squid spent $\sim 35 \%$ of nighttime hours at depths $>300 \mathrm{~m}$ (Fig. 5B). Thus, squid often descended at night to the depth range where whales were diving most often.

Based on the analyses of deep-diving by squid, we propose that the most likely reason for these deep nighttime dives concerns recovery from physiological stress experienced during foraging in warm shallower water (up to $28^{\circ} \mathrm{C}$ during the study). The archivaltagged squid dove more quickly to great depth after experiencing warmer temperatures (Fig. 8A,B) and appeared to be relatively quiescent immediately following a dive (Fig. 8C), during which time it may have been recovering. Given that the 3 squid carrying PAT tags also showed evidence of such deep nighttime diving (e.g. Fig. 6), this would appear to be a general behavioral feature of jumbo squid in this area at this time of year.

We propose that jumbo squid are more susceptible to predation by sperm whales at night while they are recovering at depth immediately following activity near the surface. In addition to being less mobile during the recovery phase itself, squid may generally be more susceptible to predation at depths $>250 \mathrm{~m}$, because this region - which is relatively cold and extremely low in dissolved oxygen content-constitutes the upper boundary of the oxygen minimum layer (OML) (Alvarez-Borrego \& Lara-Lara 1991, Gilly et al. 2006). Low temperature and hypoxia would both be expected to negatively impact overall performance of a metabolically active poikilotherm like the jumbo squid (Webber et al. 2000, Pörtner 2002).

Tagging studies have shown that jumbo squid spend a substantial amount of time in the OML and that the overall activity level can remain remarkably high at these depths (Gilly et al. 2006). However, true swimming velocities involving a horizontal component have not been measured, and quantitative evaluation of performance is not yet possible. Probably the behaviors most relevant to predation concern escape, which has not been studied for jumbo squid. Any number of relevant physiological factors may be compromised by 
cold and hypoxia, including visual dynamics, reaction time, ability to coordinate repeated escape jets and stamina to carry them out. Even modest impairment could substantially increase susceptibility to predation without grossly decreasing overall activity levels.

Squid probably actively forage within the OML during both day and night, and they may recover there following bouts of high activity in warm near-surface waters. Regardless of why the squid enter the OML, they spend much time in an environment that is hostile to most predatory pelagic fishes. Sperm whales, on the other hand, appear to take advantage of this situation. By hunting deep in this cold, hypoxic environment at night, as well as during the day, sperm whales may favor jumbo squid that are in some way compromised and thus easier to capture.

An analogous situation may exist in the Galapagos, where sperm whales were reported to dive consistently to about $400 \mathrm{~m}$ (Papastavrou et al. 1989), a depth that corresponds to the upper boundary of the OML in this area ( annual mean oxygen level of $0.5 \mathrm{mg}$ $\mathrm{ml}^{-1}$ is at $300-400 \mathrm{~m}$; see www.nodc.noaa.gov/OC5/ WOA01F/oxsearch.html). Use of the OML by other pelagic predators besides jumbo squid and sperm whales is undoubtedly a widespread and ecologically important phenomenon in the Eastern Pacific Ocean and other areas where a well-developed OML exists. Application of satellite tags to both predator and prey in such regions will shed light on important interactions in the mesopelagic world in the context of this and other oceanographic features.

Acknowledgements. This study was funded by NSF grant OCE-0437747 to N.J. and R.D. and by support to W.G. from the Census of Marine Life (Tagging of Pacific Pelagics), NSF grant OCE 0526640, the National Geographic Society (7578-04) and the David and Lucile Packard Foundation. We thank C. Arista de La Rosa who skippered R/V 'CICIMAR-XV' and assisted with data collection, M. Jorgenson for sharing the design of the tagging pole, C. Salinas for logistical support, P. Best for useful comments on the manuscript, C. Moore-Kochlacs for Matlab programming and data analysis, and B. Block, A. Boustany and C. Farwell for help with PAT tags.

Note added in proof. PAT tag 3 reported on in this paper was physically recovered in January 2007 on a beach near La Ribera, Baja California Sur. Although a complete analysis of the archieved time-series data is not yet complete, a preliminary examination has revealed deep-diving events during nighttime similar to those described in conjunction with Fig. 7.

\section{LITERATURE CITED}

Alvarez-Borrego S, Lara-Lara JR (1991) The physical environment and productivity of the Gulf of California. In: Dauphin JP, Simoneit B (eds) The Gulf and Peninsular
Province of the Californias. Am Assoc Petrol Geol Mem 47:555-567

Amano M, Yoshioka M (2003) Sperm whale diving behavior monitored using a suction-cup-attached TDR tag. Mar Ecol Prog Ser 258:291-295

Arnbom T (1987) Individual identification of sperm whales. Rep Int Whal Comm 37:201-204

Best PB (1999) Food and feeding of sperm whales (Physeter macrocephalus) off the west coast of South Africa. S Afr J Mar Sci 21:393-413

Clarke MR (1986) Cephalopods in the diet of odontocetes. In: Bryden MM, Harrison R (eds) Research on dolphins. Clarendon Press, Oxford, p 281-321

Clarke MR (1996) Cephalopods as prey. III. Cetaceans. Phil Trans R Soc Lond B 351:1053-1065

Clarke R, Paliza O (2001) The food of sperm whales in the southeast Pacific. Mar Mamm Sci 17:427-429

Drouot V, Gannier A, Goold JC (2004) Diving and feeding behaviour of sperm whale (Physeter macrocephalus) in the northwestern Mediterranean Sea. Aquat Mamm 30: 419-426

Gilly WF, Markaida U, Baxter $\mathrm{CH}$, Block BA and 6 others (2006) Vertical and horizontal migrations by jumbo squid, Dosidicus gigas, revealed by electronic tagging. Mar Ecol Prog Ser:324:1-17

Gordon JC, Steiner L (1992) Ventilation and dive patterns in sperm whales, Physeter macrocephalus, in the Azores. Rep Int Whal Comm 42:561-565

Jaquet N, Gendron D (2002) Distribution and relative abundance of sperm whales in relation to key environmental features, squid landings and the distribution of other cetacean species in the Gulf of California, Mexico. Mar Biol 141:591-601

Jaquet N, Whitehead H (1999) Movements, distribution and feeding success of sperm whales in the Pacific Ocean, over scales of days and tens of kilometers. Aquat Mamm 25: $1-13$

Jaquet N, Dawson S, Slooten E (2000) Seasonal distribution and diving behaviour of male sperm whales off Kaikoura: foraging implications. Can J Zool 78:407-419

Jaquet N, Gendron D, Coakes A (2003) Sperm whales in the Gulf of California: residency, movements, behavior, and the possible influence of variation in food supply. Mar Mamm Sci 19:545-562

Kawakami T (1980) A review of sperm whale food. Sci Rep Whal Res Inst 32:199-218

Markaida U, Hochberg FG (2005) Cephalopods in the diet of swordfish Xiphias gladius Linnaeus caught off the west coast of Baja California, Mexico. Pac Sci 59:25-41

Markaida U, Sosa-Nishizaki O (2003) Food and feeding habits of jumbo squid Dosidicus gigas (Cephalopoda: Ommastrephidae) from the Gulf of California, Mexico. J Mar Biol Assoc UK 83:507-522

Markaida U, Rosenthal JJC, Gilly W F (2005) Tagging studies on the jumbo squid (Dosidicus gigas) in the Gulf of California, Mexico. Fish Bull 103:219-226

Nigmatullin CM, Nesis KN, Arkhipkin AI (2001) A review of the biology of the jumbo squid Dosidicus gigas (Cephalopoda: Ommastrephidae). Fish Res 54:9-19

Papastavrou V, Smith SC, Whitehead H (1989) Diving behaviour of the sperm whale (Physeter macrocephalus) off the Galápagos Islands. Can J Zool 67:839-846

Pörtner HO (2002) Environmental and functional limits to muscular exercise and body size in marine invertebrate athletes. Comp Biochem Physiol A 133:303-321

Ruiz-Cooley RI, Gendron D, Aguíñiga S, Mesnick S, Carriquiry J (2004) Trophic relationships between sperm 
whales and the jumbo squid using stable isotopes of $\mathrm{C}$ and N. Mar Ecol Prog Ser 277:275-283

Ruiz-Cooley RI, Markaida U, Gendron D, Aguíñiga S (2006) Stable isotopes in jumbo squid (Dosidicus gigas) beaks to estimate its trophic position: comparison between stomach contents and stable isotopes. J Mar Biol Assoc UK 86:437-445

Scott TM, Sadov S (1997) Sperm whale, Physeter macrocephalus, sightings in the shallow shelf waters off Long Island, New York. Mar Mamm Sci 13:317-321

Watwood SL, Miller PJO, Johnson M, Madsen PT, Tyack PL (2006) Deep-diving foraging behavior of sperm whales (Physeter macrocephalus). J Anim Ecol 75:814-825

Webber DM, Aitken JP, O'Dor RK (2000) Cost of vertical locomotion and vertical dynamics of cephalopods and fish. Physiol Biochem Zool 73:651-662

Editorial responsibility: Otto Kinne (Editor-in-Chief), Oldendorf/Luhe, Germany
Whitehead H (1996) Variation in the feeding success of sperm whales: temporal scale, spatial scale and relationship to migrations. J Anim Ecol 65:429-438

Whitehead H (2002) Estimates of the current global population size and historical trajectory for sperm whales. Mar Ecol Prog Ser 242:295-304

Whitehead H (2003) Sperm whales: social evolution in the ocean. University of Chicago Press, Chicago, IL

Whitehead H, Kahn B (1992) Temporal and geographic variation in the social structure of female sperm whales. Can J Zool 70:2145-2149

Whitehead H, Macleod CD, Rodhouse P (2003) Some differences in niche breadth among some teuthivorous mesopelagic marine mammals. Mar Mamm Sci 19: 400-406

Submitted: April 26, 2006; Accepted: October 19, 2006 Proofs received from author(s): February 22, 2007 